\title{
Traumatic ruptured globe eye injuries in a large urban center
}

This article was published in the following Dove Press journal:

Clinical Ophthalmology

5 March 2013

Number of times this article has been viewed

\section{Eitan S Burstein \\ Douglas R Lazzaro}

Departments of Ophthalmology, SUNY Downstate Medical Center and Kings County Hospital Center, Brooklyn, NY, USA
Correspondence: Douglas R Lazzaro

450 Clarkson Avenue, Box 58,

Brooklyn, NY I I 203, USA

$\mathrm{Tel}+\mathrm{I} 7182455460$

Fax +I 7182455332

Email douglas.lazzaro@downstate.edu
Background: The purpose of this study was to examine patient characteristics and outcomes in a group of consecutive patients with ruptured globe eye injuries at Kings County Hospital Center, a large, urban, level 1 trauma center.

Methods: A retrospective chart review was performed to identify all patients with ruptured globe eye injuries seen between January 2009 and October 2011. Thirty-eight patients who sustained ruptured globe eye injuries from all causes were investigated for etiology and final visual outcomes

Results: Eight eyes in which vision could be assessed were evaluated as having no light perception at presentation and three of these eyes required primary enucleation. Of the 38 eyes, orbit fractures were found in 15 eyes and an intraocular foreign body was found in six eyes.

Discussion: Our cohort revealed a $37.5 \%$ rate of primary enucleation in eyes with no light perception, which we believe to be a reflection of the severity of injury. All three cases were secondary to a gunshot wound. Further, our sample, although small in size, revealed a very high percentage of eyes that were ruptured secondary to violent causes compared with other studies.

Keywords: rupture, trauma, violence, urban, epidemiology, emergency, globe

\section{Introduction}

Ocular trauma remains a major cause of visual impairment in the US nationally. Injuries occur with a broad range of severity and include simple subconjunctival injury, lid laceration, corneal abrasion, traumatic iritis, hyphema, lens injury, vitreous hemorrhage, retinal detachment, traumatic optic neuropathy, retrobulbar hemorrhage, orbit fracture, and ruptured globes. Ruptured globes represent one of the more serious consequences of trauma and often lead to some degree of permanent visual loss.

Kings County Hospital Center differs from other communities where case series on ocular trauma have been published in that previous studies have been focused specifically on the elderly, ${ }^{1}$ occurred in primarily Asian populations, ${ }^{2}$ or drawn patients from areas that were much less densely populated than Brooklyn. ${ }^{3}$ Traumatic injury to the eye in the US occurs at an incidence approaching 2.5 million per year. While estimates by the National Society to Prevent Blindness suggest that $90 \%$ of these injuries are preventable, both the number and causes of these injuries remain remarkably stable.

Large population series have demonstrated that, on an epidemiological scale, there are known factors that increase the risk of ocular trauma. In an analysis of blinding trauma from the US Eye Injury Registry containing data for 11,320 eyes, Kuhn et $\mathrm{al}^{4}$ elucidated the risk factors leading to blindness as being age over 60 years, injury by 
assault, injuries sustained on a street or highway, and trauma from fall injuries and gunshot wounds. They also noted posterior eye injury as a causative risk factor for blindness.

Another series of patients reported at a single hospital found that postoperative endophthalmitis after open globe injury occurred at a rate of $6.8 \%$, and found that delays in primary repair greater than 24 hours, a ruptured lens capsule, and wounds presenting with protein or soil contaminants were each independently associated with the development of post-traumatic endophthalmitis, with the risk being even greater when two or more of these criteria were present. ${ }^{5,6}$ The present study was undertaken to evaluate the epidemiology of traumatic ruptured globes at Kings County Hospital Center, a level 1 trauma center located in an urban area serving the majority of Kings County in Brooklyn, NY, USA.

\section{Materials and methods}

This project focused specifically on ruptured globe repairs that occurred between January 1, 2009 and October 30, 2011. A retrospective review of the operating room logbook identified 39 ruptured globe repair surgeries performed at Kings County Hospital Center during this time period using the Birmingham Eye Trauma Terminology System criteria. ${ }^{7}$ Exclusion criteria eliminated one patient with Fuchs' corneal dystrophy. We have adapted the criteria from previous case series to include age, gender, mechanism of injury, zone of injury, time of presentation to the Kings County Hospital Center emergency room, visual acuity before and after surgery, previous ocular surgery, associated bony fracture, and the presence of a foreign body within the globe. Complications during care and postoperatively were also investigated.

While previous studies have been performed using surveys and registry data ${ }^{4}$ and have examined the elderly ${ }^{1}$ or focused on rupture after keratoplasty, ${ }^{8}$ we could not find any articles examining this type of injury in a large urban setting with a predominantly African American/Afro-Caribbean population. Given the size and diversity of the patient population served by Kings County Hospital Center, this series would add valuable information to the trauma literature. The data gathered are also compared with data from the most recent American Academy of Ophthalmology Eye Injury Snapshot Project. ${ }^{9}$ The study was approved by the institutional review board at SUNY Downstate Medical Center and Kings County Hospital Center.

\section{Results}

Our study sample included 38 eyes representing 38 individual patients, with $31(81.5 \%)$ being male. At the time of presentation, the average patient age was 36 years, with the oldest being 92 years and the youngest being 3 years. Patients over 65 years of age accounted for three of the 38 cases $(7.8 \%)$, and two $(5.26 \%)$ were children under the age of 12 years. The mechanism of injury was identified to be violent in $19(50 \%)$ of the 38 cases, with seven of those $19(36.8 \%)$ resulting from gunshot wounds. Other violent means of injury included bottles to the eye $(n=2)$, a baseball bat to the eye $(n=1)$, and a hammer $(n=1)$.

The time of emergency department triage was also recorded, and of 33 patients for whom data were available (transfer patients were excluded from this measure), 17 of 33 cases $(51 \%)$ presented between the hours of $8 \mathrm{pm}$ and $4 \mathrm{am}$.

Reporting of wounds involving the eye was standardized to the Birmingham Eye Trauma Terminology System ${ }^{7}$ which has been adopted by major eye organizations worldwide. Ruptured globes fall into the category of open globe injuries, which are injuries resulting in a full-thickness laceration of the cornea and/or sclera. Wounds can be penetrating (with one entry wound and no exit wound),or perforating (a throughand-through injury with both entrance and exit wounds).

Eye injuries are also divided into zones based on anatomical location. Based on the Birmingham Eye Trauma Terminology System, zone I wounds are limited to the cornea and limbus, zone II if they involve the anterior sclera within $5 \mathrm{~mm}$ of the limbus, and zone III if they involve the sclera $5 \mathrm{~mm}$ posterior from the limbus. The zone of eye injury was determined by examining the operative report of the globe repair, and eyes were grouped according to the above classification into zones I, II, or III $(5,14$, and 19 eyes, respectively).

The extent of visual impairment at initial presentation varied greatly in our case series, ranging from normal vision $(20 / 20)$ to no light perception, with three patients unable to be assessed because of intubation and one patient being uncooperative. Of the 34 remaining patients in whom vision could be assessed, eight presented with no light perception (23.5\%), of whom three had a primary enucleation and one had a secondary enucleation. A secondary enucleation was performed in a patient who possessed better than NLP vision at presentation, for a total of five enucleations in the patients studied.

Post-repair complications were also examined. Complications were broken into segments anatomically, ie, corneal, anterior chamber, and retinal. Corneal complications ranged from pyogenic granuloma to an exposure keratopathy eventually requiring a transplant, and the total injuries in this 
category accounted for $15 \%$ of patients. Anterior chamber complications were seen at a rate of $20.5 \%$, and included traumatic recession of the angle, pigment dispersion, and iris irregularities. Retinal complications/reoperations occurred at a rate of $25.6 \%$. Patients were seen to have multiple segment complications on $12.8 \%$ of occasions. There was one instance of sympathetic ophthalmia, which occurred 6 weeks after the ruptured globe was repaired in an eye with an initial visual acuity of hand motion; the patient was immediately started on appropriate immunosuppressant therapy (mycophenolate mofetil), but thus far has declined enucleation.

Data for admission via the emergency department were also investigated. The majority of patients (51\%) presenting to the emergency department with severe ocular trauma did so between the hours of $8 \mathrm{pm}$ and 4 am (Figure 1), a time period during which the fewest hospital personnel are available.

\section{Discussion}

Ruptured globes represent one of the most serious surgical eye emergencies. Outcomes can vary from no change in visual acuity, to a blind painful eye that requires enucleation in order to prevent sympathetic ophthalmia or endophthalmitis. A number of conclusions can be drawn from this retrospective review of patient data from Kings County Hospital Center.

Kings County Hospital Center serves as the main level 1 trauma center in Brooklyn, a borough of New York City with a population that exceeds 2.5 million people. The average age of our patients was 36 years, with an overwhelming majority being African-American or Afro-Caribbean males. This is different from the demographics of Brooklyn as a whole

Causes of ruptured globes at kings county hospital vs Royal Adelaide hospital

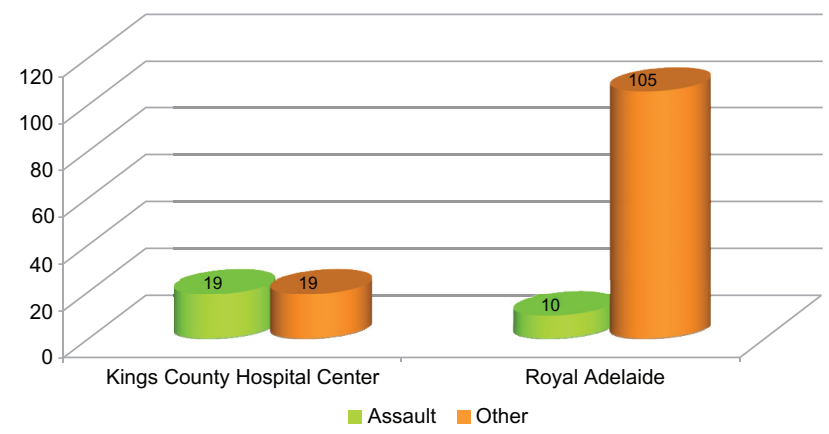

Figure I Using data from Casson et $\mathrm{al}^{3}{ }^{3}$ we compared data on the causes of ruptured globes from Kings County, a major urban hospital, to data from the Royal Adelaide Hospital, a hospital in Australia that covers both urban and rural areas. Notes: In their case series, patients were from rural areas, "disproportionately". The data revealed that intentional injury due to such varied causes as gunshots (7), bottles to the eye (2), a baseball bat to the eye (I), and a hammer (I) occurred at a much higher rate at Kings County than at the Royal Adelaide. This was confirmed with Fisher's Exact Test, showing a strongly significant difference $(P<0.0001)$.
(36.1\% African-American or Afro-Caribbean, with an average age of 34.1 years). The population is in line with the areas closest to Kings County Hospital Center, ${ }^{10}$ and represents a community under-represented in the medical literature.

There is no clear consensus as to the management of eyes with no light perception, although prognostic indicators have been examined previously. ${ }^{2}$ It is reasonable to consider the factors behind Kings County Hospital Center operative data on eyes with no light perception as causing a rate of $37.5 \%$ for primary enucleation and a rate of $50 \%$ for eyes with no light perception being enucleated overall. Of the eight eyes that had no light perception on presentation, seven were as a direct result of intentional harm, and were traumatized beyond the ability to reconstruct a useful functional eye. Further, the issue of enucleation in a blind eye is underscored by our one case of sympathetic ophthalmia, an exceedingly rare and dangerous condition affecting the fellow eye after trauma. There may be some benefit from the strategy reported by Savar et al, ${ }^{11}$ whereby patients were made appointments for one week and one month after discharge, with the opportunity to come in as needed in between. Our Kings County Hospital Center average no-show rate for return visits for all clinic appointments versus that for ruptured globes has not been determined, and perhaps an extensive conversation with patients detailing the risks and benefits of enucleation would improve no-show rates. A recent article by Soni et al ${ }^{12}$ looking at 73 eyes with open globe ocular trauma that presented with no light perception found that zone III injuries were most likely to develop no light perception and also that eyes that had some recovery at day 1 postoperatively had better final visual acuity.

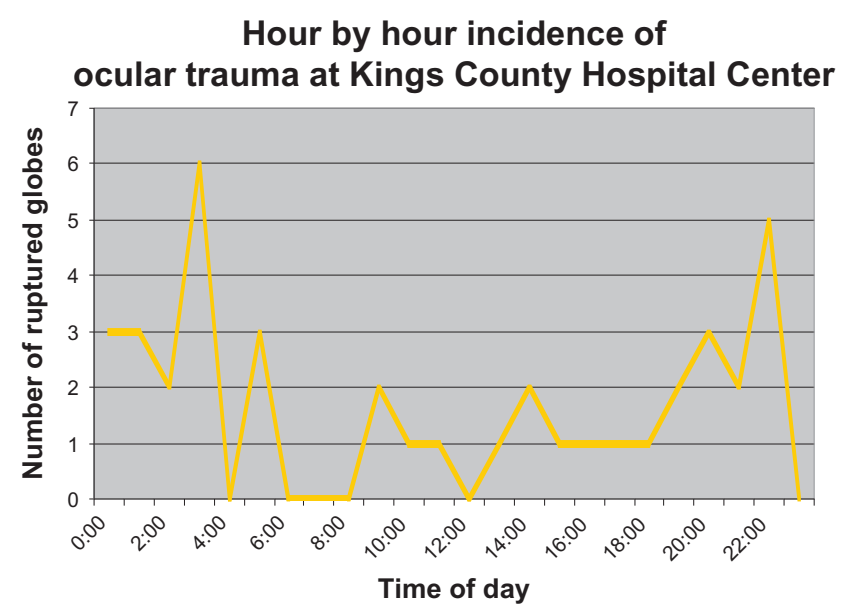

Figure 2 Emergency Department triage data was examined to see the time of day that ruptured globes presented to the hospital. Patients transferred from other hospitals were excluded. The data showed that $51 \%$ of patients presented between the hours of $8 \mathrm{pm}$ and $4 \mathrm{am}$. 
Current recommendations indicate that primary repair of the globe is most beneficial when performed within the first 24 hours and may even be protective against endophthalmitis. While this review did not assess time from injury to the operating room, the knowledge that time is a predictive factor for the prognosis of ruptured globe injury necessitates an efficient method of diagnosis and triaging of injuries, especially those that occur on overnight shifts when human resources are at their lowest. Further, patients who are sent as transfers from other institutions are subject to much longer delays in transport and triage before being seen by a consulting ophthalmologist. Standardizing the data points necessary for diagnosis could help eliminate some of those delays.

In comparing our causes of injury with those from the American Academy of Ophthalmology's Eye Injury Snapshot, our incidence of a firearm injury as the etiologic factor was $18.4 \%$ as compared with snapshot data for all traumatic injuries which reports firearm injuries to account for $1.9 \%$. Of course the number of violent injuries we saw in our small cohort of 38 patients represents only a small percentage of the total number of emergency injuries we see from all acute emergency department visits, given that many traumas do not cause a ruptured globe. Brooklyn currently has seen the highest number of homicides and shootings in New York City in $2012,{ }^{13}$ and clearly our ophthalmology service is treating only a minority of those patients wounded or killed because many may sustain injuries at body sites not involving the eye. It is of note nonetheless that violent purposeful trauma was the cause of ruptured globe injuries in $50 \%$ of our patients, with seven of our 38 patients sustaining a gunshot wound. In comparison with a study of patients treated at the Royal Adelaide Hospital $^{3}$ which examined 109 patients over 4 years, the reported rate of assault as a causative factor in ruptured globes was $9.17 \%$, which was confirmed as a statistically significant difference with Fisher's Exact test $(P<0.0001$, Figure 2). In the same study, $50.5 \%$ of patients were drawn from rural areas, while Brooklyn's total population density is 13,839 people $/ \mathrm{km}^{2}$.

\section{Disclosure}

This research was presented as a poster at the annual meeting of the Association of Research in Vision and Ophthalmology in 2012 in Fort Lauderdale, FL, USA. Otherwise, the authors report no conflicts of interest in this work.

\section{References}

1. Andreoli M, Andreoli C. Geriatric traumatic open globe injuries. Ophthalmology. 2011;118:156-159.

2. Feng K, Hu YT, Ma Z. Prognostic indicators for no light perception after open-globe injury: eye injury vitrectomy study. Am J Ophthalmol. 2011;152:654-662.

3. Casson RJ, Walker JC, Newland HS. Four-year review of open eye injuries at the Royal Adelaide Hospital. Clin Experiment Ophthalmol. 2002;30:8-15.

4. Kuhn F, Morris R, Witherspoon D, et al. Epidemiology of blinding trauma in the United States Eye Injury Registry. Ophthalmic Epidemiol. 2006;13:209-216.

5. Essex RW, Lamoureux E, Charles PG, et al. Prophylaxis for posttraumatic endophthalmitis. Arch Ophthalmol. 2008;126:742-744.

6. Essex RW, Yi Q, Charles PG, et al. Post-traumatic endophthalmitis. Ophthalmology. 2004;111:2015-2022.

7. Kuhn F, Morris R, Witherspoon CD, et al. Birmingham Eye Trauma Terminology (BETT): terminology and classification of mechanical eye injuries. Ophthalmol Clin North Am. 2002;15:139-143.

8. Kawashima M, Kawakita T, Shummura S, et al. Characteristics of traumatic globe rupture after keratoplasty. Ophthalmology. 2009;116: 2072-2076.

9. American Academy of Ophthalmology. Eye injuries: recent data and trends in the United States. Available from: http://www.aao.org/ newsroom/guide/upload/Eye-Injuries-BkgrnderLongVersFinal-1.pdf. Accessed January 26, 2013.

10. Quickfacts.census.gov [homepage on the internet]. Washington DC; US Department of Commerce, 2011. Available from: http://quickfacts. census.gov/qfd/states/36/36047.html. Accessed January 14, 2013.

11. Savar A, Andreoli MT, Kloek CE, et al. Enucleation for open globe injury. Am J Ophthalmol. 2009;147:595-600.

12. Soni NG, Bauza AM, Son JH, Langer PD, Zarbin MA, Bhagat N. Open globe ocular trauma: functional outcome of eyes with no light perception at initial presentation. Retina. 2013;33:380-386.

13. Parascandola R, Paddock B, Connor T. Crosshairs. NY Daily News. 2012;5:6.
Clinical Ophthalmology

\section{Publish your work in this journal}

Clinical Ophthalmology is an international, peer-reviewed journal covering all subspecialties within ophthalmology. Key topics include: Optometry; Visual science; Pharmacology and drug therapy in eye diseases; Basic Sciences; Primary and Secondary eye care; Patient Safety and Quality of Care Improvements. This journal is indexed on Submit your manuscript here: http://www.dovepress.com/clinical-ophthalmology-journal

\section{Dovepress}

PubMed Central and CAS, and is the official journal of The Society of Clinical Ophthalmology (SCO). The manuscript management system is completely online and includes a very quick and fair peer-review system, which is all easy to use. Visit http://www.dovepress.com/ testimonials.php to read real quotes from published authors. 